\title{
EFFECTS OF ANGIOTENSIN INFUSIONS ON ALDOSTERONE AND ELECTROLYTE EXCRETION IN NORMAL SUBJECTS AND PATIENTS WITH HYPERTENSION AND ADRENOCORTICAL DISORDERS*
}

Observations of a definite correlation in humans between the renal pressor system and aldosterone were made recently in our laboratory (Genest et al., 1959 ; Genest, Nowaczynski, et al., 1960; Biron et al., 1960, 1961 ; Genest, 1961). Our findings showed that infusions of angiotensin to normal subjects greatly increased the urinary excretion of aldosterone and of tetrahydroaldosterone, and occasionally, and to a slighter degree, that of cortisol and tetrahydrocortisone. This effect on aldosterone was confirmed by measurements of its secretion rates in normal subjects (Laragh et al., 1960) and in dogs (Mulrow and Ganong, 1961 ; Davis et al., 1961a, 1961b, 1961c ; Carpenter et al., 1961 ; Slater et al., 1961), and by incubation of slices from beef adrenal glands (Kaplan and Bartter, 1961). The failure of other hypertensive agents (Brouillet and Genest, 1958 ; Laragh et al., 1960 ; Biron et al., 1961) infused at similar pressor rates to normal subjects, to stimulate aldosterone, suggests that this phenomenon is not secondary to the increase in blood-pressure.

Angiotensin infusions are accompanied in normal subjects by marked sodium retention and a decreased urinary $\mathrm{Na} / \mathrm{K}$ ratio. Renal blood flow and glomerular filtration rate are also decreased (Bock and Krecke, 1958 ; Bock et al., 1958 ; Peart and Brown, 1961). Peart (1959) and Peart and Brown (1961) have brought evidence that hypertensive patients respond by a profuse natruresis and that the glomerular filtration rate either does not change or does not show the same degree of fall as in normal subjects during angiotensin infusions.

The purpose of the present study is threefold: (1) to study the mechanism of action of angiotensin on sodium excretion, (2) to observe the effects of angiotensin infused at subpressor rates, and (3) to extend our

\footnotetext{
*Work supported by grants from the Ministries of Health (Federal-Provincial Plan); the Life Insurance Medical Research Fund, New York; The National Institutes of Health, Washington (Project, H-6420); and the Ciba Comnany, Montreal. This work was presented in parts at the Annual Meeting of the Canadian Federation Biological Society, Winnipeg, June, 1960 and Guelph, Ontario, June, 1961 ; at the Annual Meeting of the American College of Physicians, Miami, May, 1961; at the Hahnemann Symposium on Recent Advances in Hvpertension, Philadelphia, May, 1961, and at the American Medical Association Meeting, New York, June, 1961.

†Research Fellow of the Medical Research Council of Canada, 1958-61.

$\ddagger$ Research Fellow of the Medical Research Council of Canada, 1960-2.
}

observations on angiotensin infusions to patients with various types of hypertensive disease and of adrenal disorders.

\section{Subjects and Methods}

Six normotensive subjects were studied; five were volunteer medical students whose medical history and physical examination were non-contributory. The sixth subject (G. P.) was studied while admitted to hospital for treatment of anxiety neurosis and minor gastro-intestinal symptoms. These subjects are not included in our previous publication (Biron et al., 1961).

Eight patients with benign essential hypertension were selected for this study. They were free of any serious symptoms or complications and presented normal renal function. In addition, studies were made of one patient with coarctation of the aorta, two with Addison's disease, one with Cushing's syndrome, one with primary aldosteronism, and one who had been bilaterally adrenalectomized three years previously for primary aldosteronism (bilateral hyperplasia of the zona glomerulosa) (Genest, Koiw, et al., 1960).

All subjects and patients were maintained on a fixed sodium and potassium intake (102 and $90 \mathrm{mEq} /$ day, respectively) for five to six days prior to and during the experimental period. They were studied under metabolic balance conditions for the duration of the experiment. Urine was collected every 24 hours, except on infusion days, when it was collected during the day of infusion and again separately for the rest of the 24-hour period. Synthetic valine- 5 angiotensin II aspartic $\beta$-amide (Ciba) diluted in $5 \%$ glucose was infused at a rate sufficient to maintain an average increase in diastolic pressure of 25 to $33 \mathrm{~mm}$. $\mathrm{Hg}$ in normal subjects and of 10 to $35 \mathrm{~mm}$. $\mathrm{Hg}$ in hypertensive patients. In some subjects and patients angiotensin was also given at subpressor ratesthat is, at rates insufficient to raise the diastolic pressure by more than $5 \mathrm{~mm}$. Hg. Results from control infusions of glucose $5 \%$, adrenaline, and noradrenaline in normal subjects and hypertensive patients have been described previously (Genest, Nowaczynski, et al., 1960 ; Davis et al., 1961a).

During infusions urine specimens were obtained by free voiding for hourly determination of creatinine clearance and electrolytes. To ensure adequate urine collection the patients were given an initial water load 
of 500 to $1,000 \mathrm{ml}$. two hours before the beginning of the experiment, and they received approximately $150 \mathrm{ml}$. of water every hour until the end of the hourly collection periods. In all patients in whom creatinine clearance was measured the control periods consisted of two one-hour periods immediately before and after the angiotensin infusion.

Creatinine was measured by Peters's (1942) method. Sodium and potassium were measured by flame photometry, using a Perkin-Elmer model $52 \mathrm{C}$ and lithium as internal standards. The method for urinary aldosterone determination has been described by Nowaczynski et al. (1957).

\section{Results in Normal Subjects}

The effects of pressor infusions of angiotensin for periods of one to eight hours in six normal subjects, on sodium excretion, and on creatinine clearance are shown in the Table. The percentage excretion of filtered sodium was calculated in assuming that the creatinine clearance gives a fairly close measurement of the glomerular filtration rate. All the results of creatinine clearances are corrected to 1.73 square metres of body surface area. Results of electrolytes and aldosterone excretion are expressed on a daily basis and do not take into account circadian rhythms. This way of presenting our data was the same for all subjects and patients studied. The trends observed are definite and the changes obtained are well above any variations due to diurnal variations.

The control sodium values before and after the angiotensin infusion consisted of its excretion during the day before and the night period following the infusion; the control creatinine clearance values consisted of the average of the two one-hour clearances before and after the infusion. The results indicate a mean decrease of $23 \%$ in creatinine clearance during the infusion, although in two out of the six subjects there was essentially no change. These findings confirm those of Peart (1959). Peart and Brown (1961), and of Bock et al. (1958) and Bock and Krecke (1958).

The effect of angiotensin infusions on sodium excretion was a marked reduction, averaging $63 \%$ for the group. The calculated excretion of the filtered load of sodium shows a $51 \%$ decrease.

These results illustrate the magnitude of changes in tubular rejection of sodium as compared with that of glomerular filtration rate.

In subject $R$. $L$. the intense sodium retention with the marked fall in potassium excretion and in urinary $\mathrm{Na} / \mathrm{K}$ ratio occurred without any significant change in creatinine clearance for the entire period of angiotensin infusion (Fig. 1).

In two normal subjects pressor infusions of angiotensin were compared with infusions given at a rate insufficient to raise the blood-pressure significantly. In these two subjects the subpressor infusions were accompanied by a twofold rise in aldosterone excretion and marked sodium retention, as reported previously (Genest, 1961). When angiotensin was infused at a pressor rate these responses were even more marked.

\section{Results in Patients with Benign Essential Hypertension}

The effects of 11 infusions of angiotensin on aldosterone, sodium, and potassium excretion were studied in eight patients with benign essential hypertension. The duration of these infusions varied from 2.3 to 9 hours, the rate of angiotensin administration from 0.28 to 1.25 $\mu \mathrm{g} . / \mathrm{min}$., and the increases in diastolic pressure from 6 to $26 \mathrm{~mm}$. $\mathrm{Hg}$. In each instance there was a significant increase in urinary aldosterone during the infusion period (Fig. 2). In most cases this stimulation persisted through the post-infusion period covering the time from the cessation of infusion until the following morning. This response is somewhat similar to that observed in normal subjects, where the average aldosterone excretion values of normotensive subjects include also those obtained in the subjects previously studied by us (Biron et al., 1961).

In all cases, and in contrast to the response of normal subjects, a significantly increased sodium excretion occurred during the infusions, in spite of the aldosterone stimulation. This phenomenon reverted to marked

Effects of Angiotensin Infusions on Sodium Excretion and Creatinine Clearance

\begin{tabular}{|c|c|c|c|c|c|c|c|c|c|c|}
\hline \multirow{3}{*}{ Sex } & \multirow{3}{*}{ Age } & \multirow{3}{*}{ Rate and Period of Infusion } & \multicolumn{3}{|c|}{$\begin{array}{c}\text { Sodium Excretion } \\
(\mu \mathrm{Eq} / \mathrm{min} .)\end{array}$} & \multicolumn{2}{|c|}{$\begin{array}{l}\% \text { Fxcretion of } \dagger \\
\text { Filtered Load of } \mathrm{Na}\end{array}$} & \multicolumn{3}{|c|}{$\begin{array}{l}\text { Creatinine Clearance } \\
\text { (ml. min.) }\end{array}$} \\
\hline & & & $\begin{array}{c}\text { Day } \\
\text { Before }\end{array}$ & During & $\begin{array}{l}\text { Night } \\
\text { After }\end{array}$ & Before & During & $\begin{array}{l}2 \text { Hour } \\
\text { Before }\end{array}$ & During & $\begin{array}{l}2 \text { Hour } \\
\text { After }\end{array}$ \\
\hline & & & \multicolumn{3}{|c|}{ Infusion } & \multicolumn{2}{|c|}{ Infusion } & \multicolumn{3}{|c|}{ Infusion } \\
\hline
\end{tabular}

\begin{tabular}{|c|c|c|c|c|c|c|c|c|c|c|c|c|}
\hline \multirow[b]{2}{*}{$\begin{array}{l}\text { J. L. B. } \\
\text { G. P. } \\
\text { A. L. } \\
\text { R. L. } \\
\text { R. B. } \\
\text { M. L. }\end{array}$} & \multicolumn{12}{|c|}{ Normal Subjec's* } \\
\hline & $\begin{array}{l}\mathbf{M} \\
\mathbf{F} \\
\mathbf{M} \\
\mathbf{M} \\
\mathbf{M} \\
\mathbf{M}\end{array}$ & $\begin{array}{l}24 \\
36 \\
23 \\
23 \\
23 \\
24\end{array}$ &  & 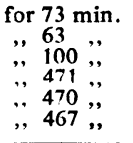 & $\begin{array}{l}58 \\
61 \\
55 \\
69 \\
50 \\
62\end{array}$ & $\begin{array}{r}5 \\
39 \\
9 \\
25 \\
10 \\
48\end{array}$ & $\begin{array}{r}15 \\
5 \\
12 \\
39 \\
25 \\
33\end{array}$ & $\begin{array}{l}0.47 \\
0.37 \\
0.26 \\
0.48 \\
0.38 \\
0.45\end{array}$ & $\begin{array}{l}0.05 \\
0.42 \\
0.07 \\
0.18 \\
0.08 \\
0.37\end{array}$ & $\begin{array}{r}94 \\
117 \\
146 \\
102 \\
90 \\
100\end{array}$ & $\begin{array}{l}72 \\
65 \\
90 \\
99 \\
89 \\
87\end{array}$ & $\begin{array}{r}83 \\
72 \\
118 \\
120 \\
108 \\
97\end{array}$ \\
\hline & & & & $\begin{array}{l}\text { Mean } \\
\text { Change }\end{array}$ & 59 & $\begin{array}{c}22 \\
-63 \%\end{array}$ & 21 & 0.39 & $\begin{array}{c}0.19 \\
-51 \%\end{array}$ & 108 & $\begin{array}{c}84 \\
-23 \%\end{array}$ & 100 \\
\hline
\end{tabular}

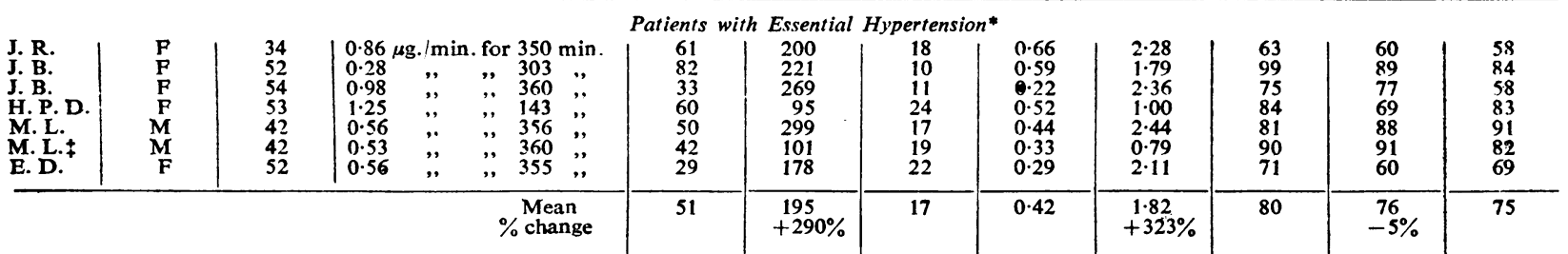

* On a fixed $\mathrm{Na}$ and $\mathrm{K}$ intake (102 and $90 \mathrm{mEq}$ day, respectively)

†ercentages for control periods " before" were derived by using the sodium excretion for the entire 24-hour period preceding the infusions and the mean creatinine clearances for the two-hour period immediately precedine the infusion. 
retention immediately after the cessation of infusion, while aldosterone stimulation still persisted (Fig. 3).

The typical effect of a pressor infusion in a patient with essential hypertension is shown in Fig. 4. Urinary aldosterone of patient J. R. rose from an average control of 16 to $114 \mu \mathrm{g}$./day during the infusion, and the increase persisted to some degree during the postinfusion period. Sodium excretion, on the other hand, increased fourfold during the infusion, with severe retention during the post-infusion period.

A subpressor infusion carried out in patient J.B. resulted in a twofold increase in aldosterone excretion, accompanied by a threefold increase in urinary sodium, thus demonstrating the sensitivity of the metabolic responses to angiotensin. The effects of a pressor infusion administered five days later were qualitatively similar but much more prominent quantitatively. Aldosterone excretion rose from a control value of $17 \mu \mathrm{g}$./ 24 hours to $54 \mu \mathrm{g}$. $/ 24$ hours during the infusion, and $135 \mu \mathrm{g} . / 24$ hours during the post-infusion period.

Of particular interest was the effect of an angiotensin infusion carried out in patient E. D. on the fifth day of administration of $4.5 \mathrm{~g}$./day of "metopirone." Despite the usual inhibitory effect of this drug on aldosterone production at the dosage used ( $4.5 \mathrm{~g}$. daily), the urinary aldosterone did not change appreciably. The pressor infusion of angiotensin produced a significant increase in aldosterone excretion from an average of 10 to $33 \mu \mathrm{g}$./day. Again, despite this rise, an eightfold rise in sodium excretion occurred during the angiotensin infusion (Fig. 5).
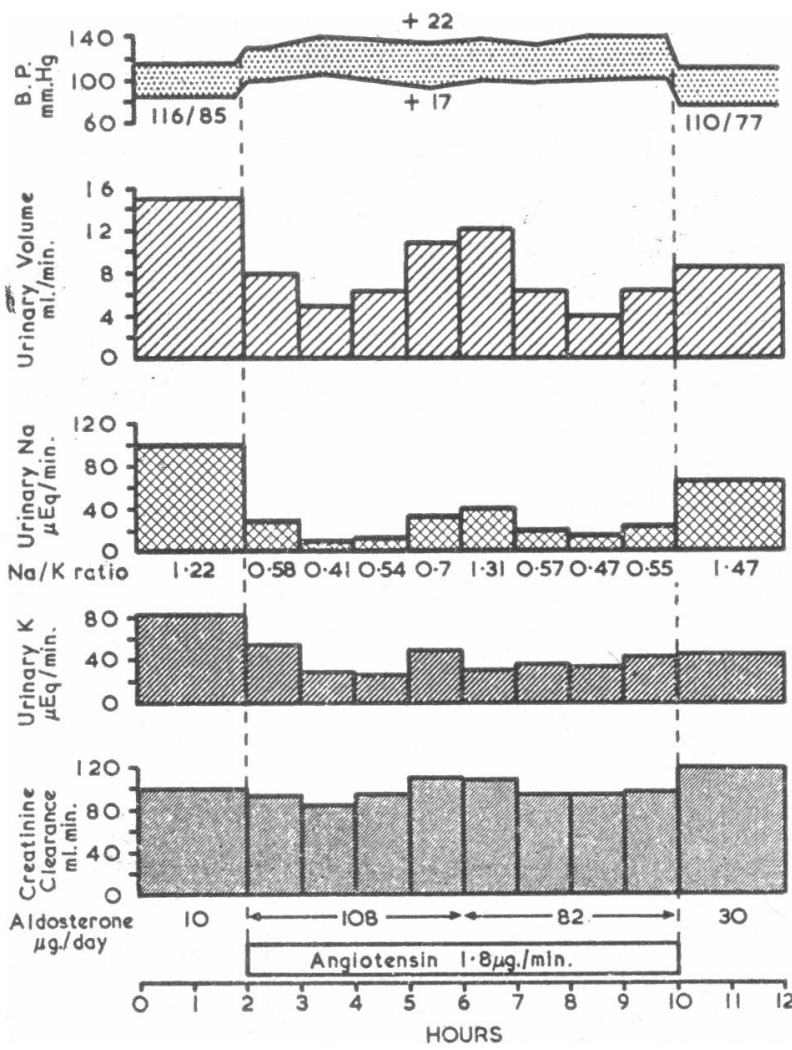

Fio. 1.-Effects of a pressor infusion (average increase of $22 / 17 \mathrm{~mm}$. $\mathrm{Hg}$ in systolic and diastolic pressures above control levels) of angiotensin (1.8 $\mu \mathrm{g} . / \mathrm{min}$. for eight hours) on urinary volume, sodium, $\mathrm{Na} / \mathrm{K}$ ratio, potassium, and creatinine clearance (corrected to 1.73 square metres of body surface area) in a normal subject (R. L.). He shows an 8- to 11-fold increase in urinary aldosterone, accompanied by a marked sodium retention which persisted throughout the infusion period without any significant change in creatinine clearance.
The effects on sodium excretion and creatinine clear. ance of seven pressor infusions of angiotensin given for periods of one to six hours to six patients with benign

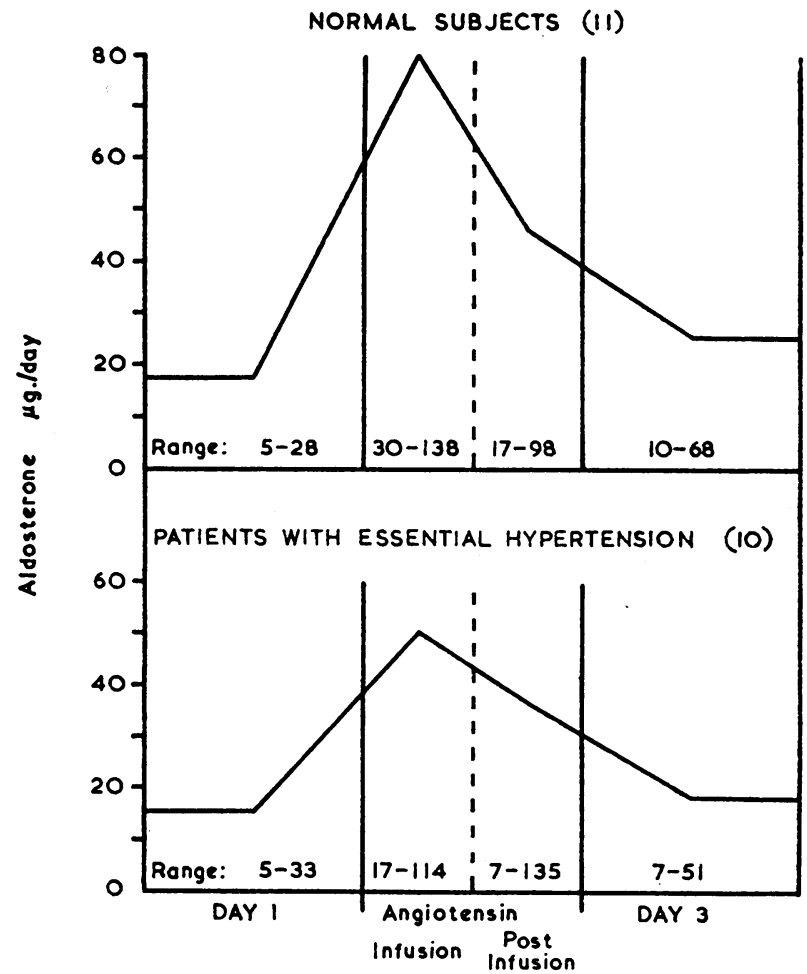

Fig. 2.-Mean aldosterone excretion and range before, during, and after pressor infusions of angiotensin to 11 normal subjects and eight patients with benign essential hypertension (10 experiments). Each subject and patient was maintained on a fixed diet containing 102 and $90 \mathrm{mEq}$ of sodium and potassium respectively per day for a period of about five days before and during the experiment. The mean aldosterone response of normal subjects is greater than that of patients with essential hypertension but with marked overlapping of individual values. NORMAL SUBJECTS (ii)



Fig. 3.-Mean urinary excretion of sodium and range before during, and after pressor infusions of angiotensin in 11 normal subjects and eight patients with essential hypertension (10 experiments). In contrast to the normal subjects and despite the greatly increased aldosteronuria, all patients with essential hypertension showed during the angiotensin infusions a marked natruresis, which was followed by severe sodium retention immediately after cessation of the infusion. These subjects and patients are the same as those of Fig. 2 and were maintained on a similar diet. 
essential hypertension are shown in the Table. In contrast to the normal subjects, creatinine clearance fell only $5 \%$ as an average for the group. Instead of the sodium retention observed in the normal subjects, there was a threefold increased excretion, with a parallel rise in urinary $\mathrm{Na} / \mathrm{K}$ ratio. It is of interest that in patient

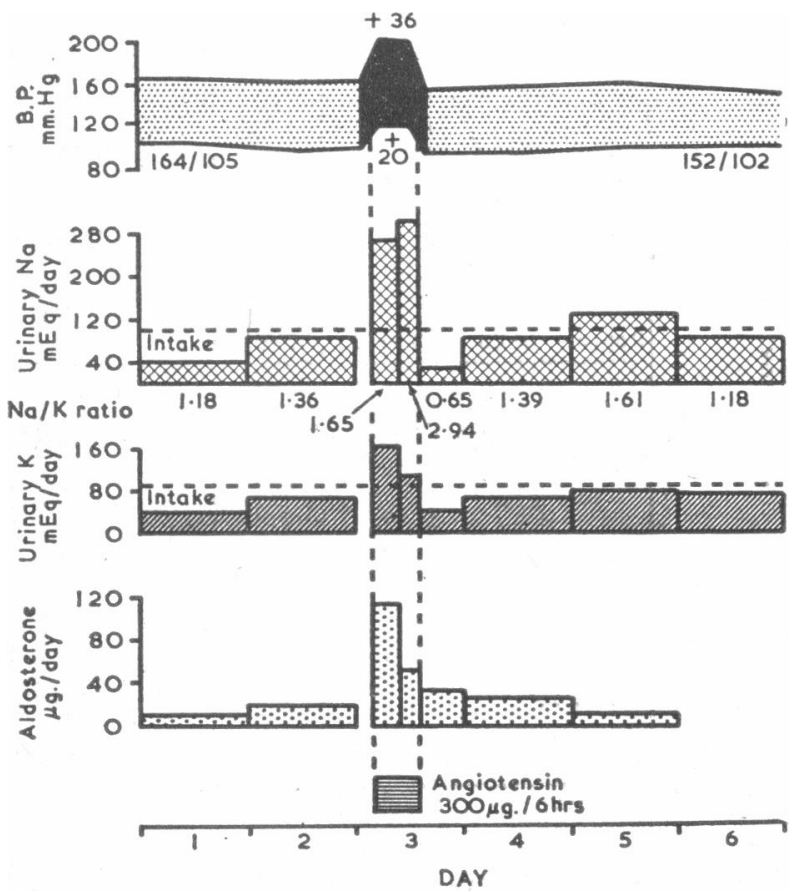

Fig. 4.-Effects of a pressor infusion (increase in blood-pressure of $36 / 20 \mathrm{~mm}$. Hg over control levels) of angiotensin $(0.83 \mu \mathrm{g} .1$ $\min$. for six hours), on urinary sodium, $\mathrm{Na} / \mathrm{K}$ ratio, potassium, and aldosterone of a patient (J. R.) with benign essential hypertension. Note the fourfold increase in sodium excretion despite the sevenfold increase in urinary aldosterone during the infusion.

M.L. a second pressor infusion of angiotensin given two days after the first infusion did not result in the same degree of natruresis.

The excretion of the filtered load of sodium in these hypertensive patients was increased by $323 \%$ as an average of the group, and shows strikingly the fundamental difference in tubular handling of sodium which exists between normals and hypertensives in response to angiotensin.

The overall effect on sodium excretion in patients with essential hypertension is compared with that observed in normal subjects (Fig. 3). While the period of infusion is characterized by a marked natruresis in hypertensive patients in contrast to sodium retention in normals, the post-infusion period shows the same degree of sodium retention in both groups.

\section{Results in Patients with Adrenocortical Disorders}

Two patients with Addison's disease who were being maintained on replacement therapy with hydrocortisone (30 mg./day) and a sodium chloride intake of $9 \mathrm{~g}$./day were given three-hour pressor infusions of angiotensin. In both cases aldosterone excretion during the infusion was increased fourfold and twofold, respectively. The effect on sodium excretion was similar to that observed in normal subjects, the observed decrease being threefold and fivefold, respectively.

Patient H. B., whose case has been previously reported in detail (Genest, Koiw, et al., 1960), had been bilaterally adrenalectomized three years before for primary aldosteronism and was normotensive for the past two years. She was given a pressor infusion of angiotensin to ascertain its effect on electrolyte excretion in the absence of endogenous adrenal steroids. There was practically no change in electrolyte excretion during or following angiotensin administration during six hours at $2.1 \mu \mathrm{g} . / \mathrm{min}$. (B.P. increase of $18 / 18 \mathrm{~mm}$. $\mathrm{Hg}$ above control level).

A pressor infusion of angiotensin to a 47-year-old woman with hypertension and the typical manifestations of Cushing's syndrome resulted in an increased sodium (from 88 to $133 \mathrm{mEq} / 24$ hours) and aldosterone (from 15 to $58 \mu \mathrm{g} . / 24$ hours) excretion during the six-hour period of administration at the rate of $0.42 \mu \mathrm{g} . / \mathrm{min}$.

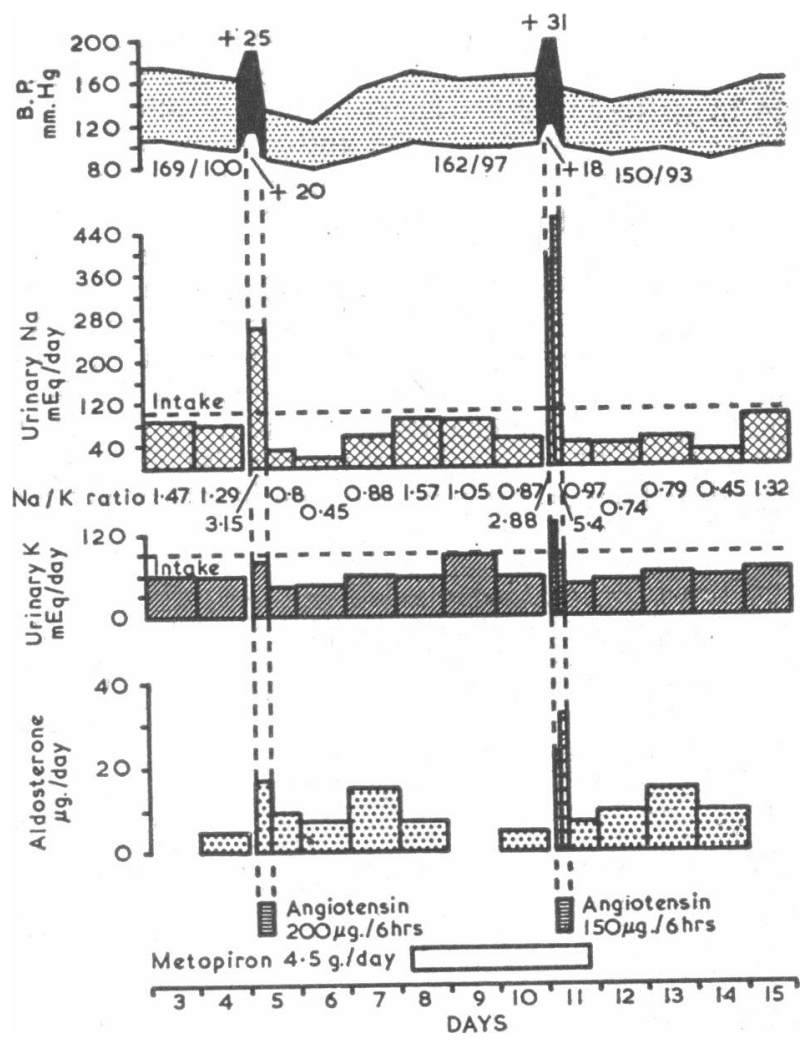

FIg. 5.-Comparison of pressor infusions of angiotensin before and during administration of an adrenal 11- $\beta$ hydroxylase inhibitor (metopirone) on urinary sodium, $\mathrm{Na} / \mathrm{K}$ ratio, potassium, and aldosterone in a patient (E.D.) with benign essential hypertension. In the control angiotensin infusion the patient showed the same aldosterone and sodium response as all other patients with essential hypertension. The administration of metopirone at $4.5 \mathrm{~g}$./ day in six divided daily doses for four days was not sufficient to block the marked stimulatory effect of angiotensin on aldosterone. Despite the increase in urinary of angiotensin on aldosterone. Despite the increase in urinary
aldosterone a very profuse natruresis was noted during the infusion

(B.P. increase of $18 / 11 \mathrm{~mm}$. $\mathrm{Hg}$ above control levels). This response is identical to that given by patients with benign essential hypertension.

To investigate the possible effect of a chronic state of hyperaldosteronism on the sodium excretory response to angiotensin, patient L. D., who presented the classical manifestations of Conn's syndrome (caused by a left adrenal adenoma and a uniformly increased zona glomerulosa in the remaining gland and in the contralateral gland), was given a six-hour pressor infusion of angiotensin $(0.19 \mu \mathrm{g} . / \mathrm{min}$. for six hours, B.P. increase of $35 / 10 \mathrm{~mm}$. $\mathrm{Hg}$ above control levels) (Fig. 6). A 
strikingly profuse natruresis occurred during the last hour of the infusion period, reaching the very high level of $719 \mu \mathrm{Eq} / \mathrm{min}$., which, if reported on a 24-hour basis, would have amounted to $1,035 \mathrm{mEq} / \mathrm{day}$, in a patient receiving an intake of only $102 \mathrm{mEq} /$ day. There was no change in urinary aldosterone-indicating in this patient the independence of the aldosterone secretion from angiotensin stimulation. The same experiment involving the infusion of angiotensin $(0.17 \mu \mathrm{g} . / \mathrm{min} . / 6$

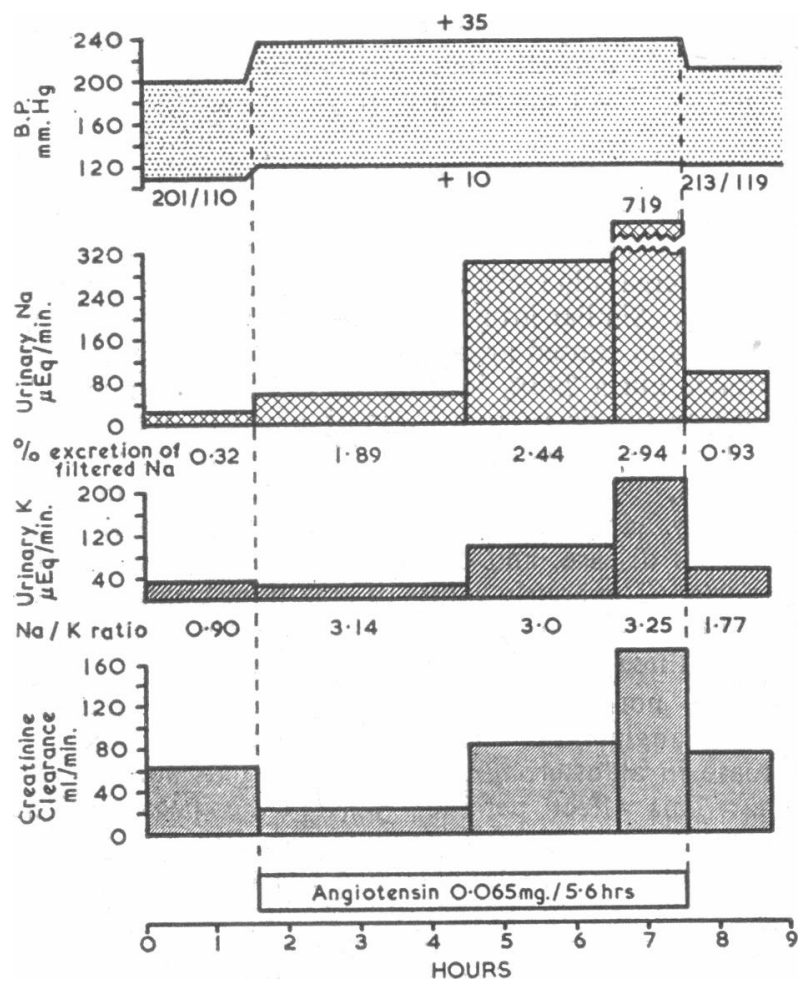

FIG. 6.-Effects of a pressor infusion (increase in blood-pressure of $35 / 10 \mathrm{~mm} . \mathrm{Hg}$ ) of angiotensin on urinary sodium, percentage excretion of filtered sodium, urinary potassium, $\mathrm{Na} / \mathbf{K}$ ratio, and creatinine clearance in a woman aged 43 with typical primary aldosteronism caused by a left adrenal adenoma. This patient was on a constant diet containing 102 and $90 \mathrm{mEq}$ of sodium and potassium respectively per day. Note the extremely high degree of sensitivity of the blood-pressure response to angiotensin (rate of infusion, $0.2 \mu \mathrm{g} . / \mathrm{min}$.) and the progressive and phenomenal natruresis reaching $719 \mu \mathrm{Eq} / \mathrm{min}$. during the last hour of infusion. This coincided with a striking rise in creatinine clearance. But a study of the percentage excretion of the filtered sodium showed that the natruresis was mainly due to a decreased tubular reabsorption of sodium. Potassium excretion was also greatly increased. Another very interesting feature was the failure of any rise in urinary aldosterone, which remained at the same control levels of 40 to $50 \mu \mathrm{g}$. during and after the infusion.

hours) at a pressor rate (increase in systolic and diastolic pressure of $42 / 12 \mathrm{~mm}$. $\mathrm{Hg}$ ) was repeated 17 days after surgical removal of the adrenal adenoma. This time urinary aldosterone rose sixfold from a control value of 11 to $66 \mu \mathrm{g}$./day during the infusion, without any significant change in sodium excretion.

Coarctation of Aorta.-In view of the possible relationship between the renal-artery perfusing pressure and the type of sodium excretory response to angiotensin, an infusion was carried out in a 12-year-old girl with coarctation of the aorta whose lower-limb arteries were not palpable even during the pressor infusion. This infusion produced a significant degree of sodium retention and a twofold increase in urinary aldosterone, findings which are entirely similar to those observed in normal subjects.

\section{Discussion}

In expressing or reporting all our results in terms of milliequivalents or micrograms per day, we have neglected the circadian rhythms of aldosterone, sodium, and potassium excretion and of creatinine clearance for the following reasons. First, it is most difficult in an experimental design, such as in the present study, to have precontrol urine collections of the same periods of time as those during angiotensin infusions, since we do not know how and for how long a given patient will tolerate such pressor infusions. Secondly, if the control urinary collection had been of the same length of time as those made during the angiotensin infusions-that is, for two, four, and even six hours-urinary aldosterone during the control periods would have been at a barely measurable level. Thirdly, the way of expressing the results was the same for all subjects and patients studied. Fourthly, and most important, the changes noted in the excretion of aldosterone and sodium are of such an order that they are well above the limits of possible changes due to diurnal variations. If, therefore, the absolute values had relative meaning, the magnitude of the changes and the trends observed are highly significant.

A large body of evidence, reviewed by Tobian (1960a, 1960b) has suggested a relationship between renin, the adrenal zona glomerulosa (or "mineralocorticoid" hormone), and sodium. Of particular interest was the demonstration, by Deane and Masson (1951), Hartroft et al. (1959), and Gross (1960), that renin administration increases the width of the adrenal zona glomerulosa in rats. It was shown in this laboratory that hypertensive infusions of angiotensin in normal subjects are accompanied and/or followed by a twofold to elevenfold increase in aldosterone excretion (Biron et al., 1960, 1961 ; Genest, Nowaczynski, et al., 1960 ; Genest, 1961). This was soon confirmed by Laragh et al. (1960), who reported the stimulatory action of angiotensin on aldosterone secretion rate in normotensive subjects. Studies by Mulrow and Ganong (1961), Slater et al. (1961), Davis et al. (1961a, 1961b, 1961c), and Carpenter et al. (1961) in nephrectomized dogs showed that renin and angiotensin infusions promptly and markedly increased aldosterone secretion, and also stimulated the production of 17-hydroxycorticosteroids, although to a less extent. These findings in dogs may indicate a species difference, since such effects on the 17-hydroxycorticoids in normal human subjects were generally smaller in magnitude or absent (Genest, 1961 ; Genest et al., 1961).

Angiotensin was detected in the blood of only one out of five patients with Conn's syndrome (Biron et al., 1962) (in this patient, angiotensinaemia was well within the range of normal subjects), using the procedure of Boucher et al. (1961); the evidence available at the present time does not suggest that angiotensin liberation is responsible for the hyperaldosteronism of Conn's syndrome. Our studies of blood angiotensin levels (Biron et al., 1962) in patients with various types of hypertension even suggest at this time that angiotensin may be more concerned with the maintenance of "normal" blood-pressure than with the production of hypertensive disease and are in agreement with Gross's (1960) observations. The prevention of aldosterone stimulation secondary to haemorrhage in dogs by nephrectomy (Davis et al., 1961a, 1961b, 1961c ; Carpenter et al., 1961) indicates that, at least in this 
experimental condition, the renal pressor system is responsible for hyperaldosteronism.

The stimulation of the zona glomerulosa does not seem to be dependent upon the systemic increase in blood-pressure, since subhypertensive infusions of angiotensin are effective, and infusions with other pressor agents (noradrenaline, phenylephrine, and adrenaline) are not (Brouillet and Genest, 1958 ; Genest, 1961 ; Genest et al., 1961). The exact mechanism of action of angiotensin on the adrenal cortex remains to be demonstrated.

The present study indicates that hypertensive patients respond to angiotensin in the same fashion as normotensives so far as aldosterone excretion is concerned.

Studying the effects of 50-minute infusions of angiotensin in normal subjects, Bock and Krecke (1958) observed an initial fall in para-aminohippuric acid (P.A.H.) and inulin clearance which tended to return to pre-control values during the infusion; the excretion of sodium was markedly depressed, and that of potassium to a less extent. During 45 minutes' infusions, Barrett et al. (1961) found that angiotensin reduced urine volume by as much as $85 \%$, inulin clearance up to $45 \%$, and that of P.A.H. up to $60 \%$, in normotensive subjects. Peart (1959) observed a reduction of both clearances, with a slight increase in filtration fraction, accompanied by a marked sodiumand-water retention. The studies of our group (Biron et al., 1960, 1961 ; Genest, Nowaczynski, et al., 1960 ; Genest, 1961), and of those of Laragh et al. (1960), Peart (1959), and Peart and Brown (1961) have shown that sodium retention consistently occurred in normal subjects during infusions lasting for 5 to 24 hours. Present data obtained with infusions lasting from one to eight hours in six normotenive subjects show a mean decrease of $23 \%$ in creatinine clearance, while sodium excretion was diminished by $63 \%$ below control values.

An inconsistent natruretic response to angiotensin (purified angiotensin solution) in hypertensive patients was reported by Dustan et al. (1955) and Nijensohn (1957). But a more thorough study made by Peart and Brown (1961) with a purer synthetic preparation revealed that angiotensin infusions in hypertensive patients caused almost no change in inulin clearance, a slight decrease in P.A.H. clearance, and a marked natruresis and diuresis. Our data obtained with infusions lasting from one to six hours in six patients show a mean decrease of $5 \%$ in creatinine clearance, accompanied by a $290 \%$ increase in sodium excretion. The failure of the creatinine clearance to fall significantly in hypertensive patients during angiotensin infusions points to an important difference in renal haemodynamics as compared with that of normal subjects. Our findings confirm the results obtained by Peart. The second fundamental characteristic concerns the striking difference in the sodium excretory response of the hypertensive patients as compared with the normal subjects; the $323 \%$ increased excretion of the filtered load of sodium observed in hypertensive patients in response to angiotensin stands in marked contrast to the $51 \%$ reduction noted in normal subjects, strongly suggesting that angiotensin has opposite effects on the tubular handling of sodium in these two groups of subjects.

The patient with coarctation of the aorta behaved like a normal subject with respect to sodium excretion. Peart and Brown (1961) have found that acute lowering of systemic blood-pressure does not alter the natruretic response in hypertensives, but in five patients with hypertension they observed a return to a normal sodium response after a few months of normotension following nephrectomy or drug therapy.

Del Greco (1961) has found that, in one patient with advanced essential hypertension, angiotensin infusion under conditions of sodium retention promoted natruresis and diuresis while it tended to cause a decreased excretion of salt and water under conditions of sodium depletion. This interesting observation does not apply readily to our findings, however, since our patients had normal renal function and were receiving a " normal" salt intake (6 g./day).

\section{Summary and Conclusion}

Angiotensin infusions lasting from one to six hours in six normotensive subjects caused an average drop of $23 \%$ in creatinine clearance and of $63 \%$ in sodium excretion. Similar infusions in six patients with essential hypertension caused an average fall of $5 \%$ in creatinine clearance but a $290 \%$ increase in sodium excretion. A similar natruretic response was obtained in one patient with Cushing's syndrome and one with primary aldosteronism, while sodium retention occurred in one bilaterally adrenalectomized patient, two patients with Addison's disease, and one patient with coarctation of the aorta. The hourly values of creatinine clearance and of sodium excretion did not show a close relationship between these two parameters.

In all normal subjects and hypertensive patients studied, angiotensin caused a consistent and marked increase in aldosterone excretion during its administration. This effect persisted during the post-infusion period, at which time it was accompanied by marked sodium retention. The metabolic effects of angiotensin infusions may be produced without increasing the systemic blood-pressure, since subpressor infusions had qualitatively similar effects to those obtained by infusions given at pressor rates.

The greater effect on sodium tubular reabsorption than on glomerular filtration rate in normotensive subjects suggests a direct action on tubular transport of sodium, probably through the effect of the increased aldosterone. The virtual absence of marked decreases in glomerular filtration rate and the prominent natruretic response observed in hypertensive patients point to interesting haemodynamic and tubular differences.

We wish to express our gratitude to Drs. Walter Murphy, Carl Schaffenburg, and Franz Gross, Ciba Company, Montreal and Basle, for generous gifts of valine-5 angiotensin II (preparation 19990-A) and of metopirone; to Misses Lucienne Monette, Isabelle Morin, Denyse Landriault, Claudette Laniel, and Alice Laflamme for their technical assistance ; to Mrs. Anne Brossard, dietitian; to Misses F. Salvail, P. Bourque, and R. Roy, nurses; and to Miss $\mathrm{J}$. Morin for the illustrations.

\section{REFERENCES}

Barrett, J. C., McNeil, J. H., and Murdaugh, H. V. (1961). Clin. Res., $9 ., 34$

Biron, P., Boucher, R., Chrétien, M., and Genest, J. (1962). Data to be published.

Koiw, E., Nowaczynski, W., Brouillet, J., and Genest, J. (1961). J. clin. Invest., 40, $33 \ddot{8}$.

Soc., 3,14

Bock, K. D., Dengler, H., Krecke, H. J., and Reichel, G. (1958). Klin. Wschr., 36, 808

- and Krecke, H. J. (1958). Ibid., 36, 69.

Boucher, R., Biron, P., and Genest, J. (1961). Canad. J. Buchem., 39, 581.

Brouillet, J., and Genest, J. (1958). Canad. Fed. Biol. Soc. (Abstracts of Proceedings), p. 10. 
Carpenter, C. C. J., Davis, J. O., and Ayers, C. R. (1961). J. clin Invest. 40. 2026

Davis, J. O., Ayers, C. R., and Carpenter, C. C. J. (1961a). Ibid., 40. 1466.

Carpenter, C C. J., Ayers, C. R., Holman, J. E., and Bahn, R. C. (1961b). Fed. Proc., 20, 178.

-1 - (1961c). J. clin. Invest., 40, 684.

Deane, H. W., and Masson, G. M. C. (1951). J. clin. Endocr., 11, 193

Del Greco, F. (1961). Proc. Soc. exp. Biol. (N.Y.), 107, 943.

Dustan, H., Nijenson, C., and Corcoran, A. C. (1955). J. clin. Invest., 34, 931.

Genest, J. (1961). Canad. med. Ass. J., 84, 403

- Biron, P., Koiw, E., Nowaczynski, W., Chrétien, M., and Boucher, R. (1961). Circulat. Res., 9. 775

Koiw, E., Beauregard, P., Nowaczynski, W., Sandor, T. Brouillet, J., Bolte, E., Verdy, M., and Marc-Aurèle, J. (1960). Metabolism, 9, 624 .

- Nowaczynski, W., and Sandor, T. (1959). Circulation, 20, 700 .

Nowaczynski, W., Koiw, E., Sandor, T., and Biron, P. (1960). Ciba Symposium on Essential Hypertension, edited by K. D. Bock and P. T. Cottier, p. 126. Springer-Verlag, Heidelberg.

Gross, F. (1960). Ibid., p. 92

Hartroft, P. M., Newmark, L. N., and Pitcock, J. A. (1959) Hypertension, edited by J. H. Moyer, p. 24. Saunders, Philadelphia.

Kaplan, N. M., and Bartter, F. C. (1961). Abstract, 43rd Meeting. Endocrinological Society.

Laragh, J. H., Angers, M., Kelly, W. G., and Lieberman, S. (1960) J.' Amer. med. Ass., 174, 234.

Mulrow, P. J., and Ganong, W. F. (1961). American Society for Clinical Investigation, 53rd Annual Meeting, Atlantic City. Nijensohn, C. M. (1957). Sem. méd. (B. Aires), 111, 205.

Nowaczynski, W., Koiw, E., and Genest, J. (1957). Canad. J. Biochem., 35, 425.

Peart, W. S. (1959). Brit. med. J., 2, 1421.

Peand Brown, J. J. (1961). Lancet, 1, 28.

Slater, J. D. H., Casper, A. G. T., Delea, C. S., and Bartter, F. C. (1961). Clin. Res., 9. 209 .

Tobian, L. (1960a). Ann. intern. Med., 52, 395.

(1960b). Physiol. Rev., 40, 280.

\section{LONG-TERM STEROID THERAPY IN CHRONIC INTRACTABLE ASTHMA A STUDY OF 317 ADULT ASTHMATICS ON CONTINUOUS STEROID THERAPY FOR AN AVERAGE PERIOD OF $2 \frac{1}{2}$ YEARS}

HARRY A. REES,* M.B., B.Sc., M.R.C.P. Registrar, St. David's Hospital, Cardiff

The purpose of this paper is to assess the value and risks of long-term steroid therapy in severe chronic asthma. The observations are based on 317 asthmatic out-patients treated with steroids for periods of from four months to seven years, with an average duration of two and a half years: 205 have been on steroids for over two years, 118 for over three years, 46 for over four years, and 12 for over five years.

Steroids were first described as beneficial in asthma by Bordley et al. (1949). The Medical Research Council (1956a) confirmed their efficacy in status asthmaticus but doubted their value in the long-term treatment of chronic asthma (M.R.C., 1956b).

There are now many favourable reports on the value of long-term steroid therapy in chronic intractable asthma (Gay et al., 1954 ; Arnoldsson, 1958 ; Williams, 1959 ; Phear et al., 1960 ; Serafini, 1960 ; Andersson and Bruun, 1960 ; Herxheimer, 1961 ; Pearson et al., 1961 ; Livingstone and Davies, 1961 ; Baldwin et al., 1961). That there is still confusion of thought on this subject is shown by the recent communications of Grant (1961), Asher (1961), Maxwell (1961), and Hart and Emerson (1961).

\section{Materials and Methods}

Care has been taken to include only patients with asthma, which we have defined as recurrent spontaneous attacks of dyspnoea and wheeziness, commonly occurring at night, due to a functional bronchiolar obstruction with a characteristic pathology (Gough, 1960). The numbers of patients with associated conditions are shown in Table I. Care was taken to include only those with "chronic intractable asthma" in whom all other measures had failed; 133 patients $(42 \%)$ had had repeated status asthmaticus. The pretreatment assessment is shown in Table IV. Of these 317 patients, $84 \%$ were to a greater or less degree chronically incapacitated, $32 \%$ permanently so. All of the $16 \%$ not incapacitated had considerably disturbed sleep at night and were dyspnoeic on exertion in spite of treatment. During the last two years all patients

*Now at Llandough Hospital, Cardiff.

\section{A. WILliaMS, M.D., M.Sc., F.R.C.P.} Physician, St. David's Hospital, Cardiff

had simple lung-function tests before and during steroid therapy. No patients were started on steroid therapy unless they had a very low forced expiratory volume in 1 second (F.E.V..$_{1}$ ) and forced vital capacity (F.V.C.), and none were maintained on steroid therapy unless there had been a marked increase in the F.E.V..$_{1}$ and F.V.C. over an initial period of two weeks. This improvement was generally maintained except when other factors such as a chest infection supervened.

We would regard as a typical response an F.E.V..$_{1}$ of $750 \mathrm{ml}$., an F.V.C. of 1,533 ml., and an F.E.V.\% 48 ; 14 days later F.E.V. ${ }_{1}$ 2,233 ml., F.V.C. 3,400 ml., and F.E.V.\% 60.

Patients were skin-tested as indicated by the clinical history and hyposensitization was carried out in appropriate cases. An E.N.T. surgeon (Mr. Alun Thomas) and a psychiatrist (Dr. Cyril Jenkins) examined and treated appropriate patients.

The age-and-sex distribution is shown in Table II. The male:female ratio was $1: 2.6$. Of the patients, $90 \%$ were over 30 years, $73 \%$ over 40 , and $85 \% 30$ to 69 . No children were included, as only aduits are seen at this clinic.

Prednisone was given to 279 patients ( $88 \%$ ), cortisone or hydrocortisone to $13(4 \%)$ because they preferred

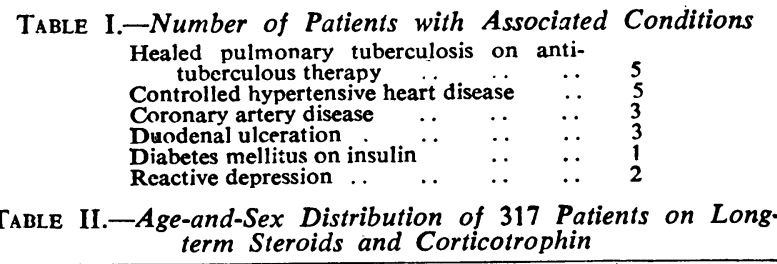

\begin{tabular}{c|c|c|c|c}
\hline \multirow{2}{*}{$\begin{array}{c}\text { Age } \\
\text { in }\end{array}$} & \multicolumn{3}{|c|}{ Steroids and Corticotrophin } & \multirow{2}{*}{ Percentage } \\
\cline { 2 - 4 } Years & Male & Female & Total & \\
\hline $20-19$ & 2 & 6 & 8 & 3 \\
$20-29$ & 9 & 14 & 23 & 7 \\
$30-39$ & 19 & 36 & 55 & 17 \\
$40-49$ & 16 & 44 & 60 & 19 \\
$50-59$ & 28 & 63 & 91 & 29 \\
$60-69$ & 11 & 54 & 65 & 20 \\
$70-79$ & 4 & 11 & 15 & 5 \\
\hline Total & 89 & 228 & 317 & 100 \\
\hline
\end{tabular}

